\title{
The Aroma Composition of Baby Ginger Paocai
}

\author{
Songming Luo, Qiang Li, Anjun Chen, Xingyan Liu, and Biao Pu
}

College of Food Science, Sichuan Agricultural University, Yaian 625014, China

Correspondence should be addressed to Biao Pu; pubiao2002@163.com

Received 27 June 2017; Revised 23 August 2017; Accepted 11 September 2017; Published 25 October 2017

Academic Editor: Yuanyuan Zhang

Copyright (c) 2017 Songming Luo et al. This is an open access article distributed under the Creative Commons Attribution License, which permits unrestricted use, distribution, and reproduction in any medium, provided the original work is properly cited.

\begin{abstract}
The purpose of this study was to analyze the volatile compounds in baby ginger paocai and the fresh baby ginger and identify the key aroma components that contribute to the flavor of baby ginger paocai. A total of 86 volatile compounds from the two baby ginger samples were quantified; these compounds were extracted by headspace solid-phase microextraction (HS-SPME) and analyzed by gas chromatography-mass spectrometry (GC-MS). The aroma composition of baby ginger paocai was different from that of fresh baby ginger. Baby ginger paocai was characterized by the presence of aroma-active compounds which varied in concentration from 0.03 to $28.14 \%$. Geranyl acetate was the aroma component with the highest relative content in baby ginger paocai. $\beta$-myrcene, eucalyptol, trans- $\beta$-ocimene, Z-ocimene, linalool, decanal, cis-citral, geraniol, geranyl acetate, curcumene, and $\beta$-bisabolene contributed to the overall aroma of the product of baby ginger paocai which had gone through a moderate fermentation process.
\end{abstract}

\section{Introduction}

Baby ginger, which is a kind of ginger rhizomes (Zingiber officinale Roscoe), is often referred to as "immature ginger" or "young ginger" or "tender ginger." In virtue of its agreeable flavor, good texture, and health function, baby ginger is consumed as a kind of vegetable by more and more people in the world [1]. Baby ginger will wilt within 2 days under the normal temperature. If fresh baby ginger was treated by the measure proposed by Liu et al. [2], its commodity rate could reach $95 \%$ and $80 \%$ after $24 \mathrm{~d}$ and $30 \mathrm{~d}$, respectively. An et al. [3] found that the method of intermittent microwave and convective drying for ginger was a very promising drying method for its quality retention, but dried ginger products were limited for use. In order to meet the consumer's demand for baby ginger in nonharvesting season, novel products of baby ginger are developed, such as baby ginger paocai (which is also referred to as "pickled baby ginger" or "pao zi jiang" in Chinese), frozen baby ginger, and instant baby ginger slices.

Ginger paocai, as a Chinese pickle, has been consumed by the people of Sichuan province in China for a long time [4]. In China, the production of a paocai often needs to go through a fermentation process assisted by brine $[5,6]$. Ginger paocai production could be not only a solution to improving the flavor of raw ginger, but also a solution to helping to increase the consumption of this functional food. However, the quality of baby ginger paocai will be affected by the fermentation conditions. For example, the amount of salt could influence the sensory quality of the fermented vegetables [7].

In quality indices, aroma is one of the most appreciated characteristics that confirm the initial impression of consumers. Recently, there were many researches on the aroma composition of food, and the experts in these studies believed that the flavor of food was different with its type. Furthermore, some volatile compounds of some food products are not detected by consumers because of their thresholds and interactions with other compounds [8]. The headspace solidphase microextraction (HS-SPME) conditions of volatile compounds in ginger were optimized by $\mathrm{Yu}$ et al. [9]. Chavalittumrong and Jirawattanapong [10] analyzed variation of active components of Curcuma domestica rhizome at different growth stages. Bartley and Jacobs [11], Huang et al. [12], and An et al. [3] analyzed the effects of drying methods on volatile compounds in ginger, respectively. As yet, there are very few studies on the quality of baby ginger paocai. Therefore, our aims were to analyze the volatile compounds obtained by headspace solid-phase microextraction (SPME) 
from the fresh baby ginger and baby ginger paocai, and compare their flavor composition, and to identify the key aroma components that really contribute to the flavor of this pickle product, so that we would explore the relationship between micro ecology and quality changes of baby ginger during its fermentation process. Furthermore, The results of this research would be helpful to the process optimization and quality control of baby ginger paocai.

\section{Materials and Methods}

2.1. Materials. Baby ginger paocai was sampled from Yingu Food Inc. located in Chengdu, China. The baby ginger paocai was produced according to the processing method and the particular steps described in subsequent content. Firstly, the selected fresh baby ginger samples were washed in water jet washer and then drained. After being cut, 8 kilograms of fresh baby ginger was put into one of the 25-litre pottery jars which were washed, sterilized, and cooled in advance. Before the baby ginger samples were put into the jar, the jar had 16 litres of $4 \%$ saline water, so that the baby ginger paocai was slightly salted. Then 60 grams of bacterial powder, as a starter culture for the baby ginger fermentation, was added to the jar. There were $1.5 \times 10^{10} \mathrm{cfu}$ active lactic acid bacteria in each gram of the bacterial powder. Finally, the jars were sealed and placed in a room where the temperature was $25 \pm 2^{\circ} \mathrm{C}$.

On the 7th day of the baby ginger fermentation, the baby ginger paocai was sampled and stored in a refrigerator at $4^{\circ} \mathrm{C}$. The fresh baby ginger was also sampled from this food company and stored in a freezer at $4^{\circ} \mathrm{C}$ prior to analysis, in order to compare its flavor formation with that of baby ginger paocai. The fresh baby ginger, as the raw material for baby ginger paocai, was of good quality and short of serious mechanical damage. The collected baby ginger samples were of similar length (about $6 \pm 1 \mathrm{~cm}$ ) while they had hardly any fibrous parts except for their outer skins.

A mixture of n-alkanes (C7-C40, $1000 \mathrm{mg} / \mathrm{L}$ each component in hexane) was purchased from o2si smart solutions (Charleston, USA). Decane, which was used for quantitative analysis of volatile compounds, was purchased from LGC Labor GmbH (Augsburg, Germany).

2.2. Extraction of Volatile Compounds. Researchers usually cut and crush the samples for aroma analysis, so that the aroma substances are extracted completely. In order to exhibit the overall flavor of the baby ginger samples, every sample was sliced, chopped, and mixed together. And then, using the random sampling method, $5 \mathrm{~g}$ of the chops mixture was obtained and put in a headspace bottle. All parameters were analyzed and determined at least in triplicate at each sampling time.

After comparing the extraction characteristics of several kinds of SPME fibers (such as PDMS, PDMS/DVB, Carboxen/PDMS, and DVB/CAR/PDMS), the authors selected a stableflex 50/30 $\mu \mathrm{m}$ DVB/CAR/PDMS fiber $(1 \mathrm{~cm}$, Supelco, Bellefonte, PA, USA) for the extraction and concentration of volatile compounds of baby ginger. Before being used to extract volatile compounds of baby ginger, the SPME fiber was cleaned thermally at $270^{\circ} \mathrm{C}$ for $1 \mathrm{~h}$.
The optimum sampling conditions of aroma compounds in baby ginger samples with the DVB/CAR/PDMS fiber were investigated. Before the aroma components were extracted by the fiber, there was a partition equilibrium of the aroma components between the crushed baby ginger and the headspace of the bottle. The process of the equilibrium of aroma components was conditioned at $45^{\circ} \mathrm{C}$ for $30 \mathrm{~min}$. And then the DVB/CAR/PDMS fiber was exposed to the headspace for $30 \mathrm{~min}$ at $45^{\circ} \mathrm{C}$ so that the fiber could enrich aroma components completely.

2.3. Gas Chromatography-Mass Spectrometry (GC-MS) Anal$y$ sis. The volatile compounds of baby ginger were identified by the method of gas chromatography-mass spectrometry (GC-MS). The gas chromatograph, whose model was Agilent $7890 \mathrm{~A}$, was equipped with a HP-5MS capillary column $(30 \mathrm{~m} \times 0.25 \mathrm{~mm} \times 0.25 \mu \mathrm{m}$, Agilent technologies). Helium was used as the carrier gas and its flow rate is $1 \mathrm{~mL} / \mathrm{min}$ in the HP-5MS capillary column. The SPME fiber, which concentrated the aroma components in advance, was exposed into the injection port of the gas chromatography (GC) at $250^{\circ} \mathrm{C}$ for $5 \mathrm{~min}$ in the splitless mode, so that the aroma components were desorbed completely. To separate all the aroma components of baby ginger, the gas chromatography was run under a specialized oven temperature program. On the basis of reference to the analytical methods [3, 13], the optimized temperature program was as follows: the temperature was initially kept at $50^{\circ} \mathrm{C}$ for $1 \mathrm{~min}$ and increased by $4^{\circ} \mathrm{C} / \mathrm{min}$ to $110^{\circ} \mathrm{C}$ and maintained for $5 \mathrm{~min}$; afterwards, it was increased by $1^{\circ} \mathrm{C} / \mathrm{min}$ to $135^{\circ} \mathrm{C}$ and kept for $3 \mathrm{~min}$ and then increased by $10^{\circ} \mathrm{C} / \mathrm{min}$ to $230^{\circ} \mathrm{C}$ and held for $3 \mathrm{~min}$ and finally returned to $50^{\circ} \mathrm{C}$. The model of the mass spectrometry was Agilent 5975C. Mass spectra were recorded at $70 \mathrm{eV}$ in the ionization mode of electron impact ion source (EI) with a solvent delay of 3 minutes and were scanned in the $\mathrm{m} / \mathrm{z}$ range of 50-550 amu with $2.91 \mathrm{scan} / \mathrm{s}$. The temperature of the electron impact ion source (EI) was $230^{\circ} \mathrm{C}$.

The mass spectra of the volatile compounds of baby ginger were compared with the data system library (NIST 11) and authentic references [14]. And the data whose matching degrees were more than 80 could be used for qualitative analysis and quantitative analysis. When the spectral peaks were analyzed qualitatively, their retention indexes (RI) were computed with the mixture of $\mathrm{n}$-alkanes. The mass spectra of the mixture of $\mathrm{n}$-alkanes were obtained by using the same HSSPME conditions and GC-MS conditions as those of the baby ginger samples.

2.4. Gas Chromatography-Olfactometry (GC-O) Analysis. GC-O analysis was performed on a GC equipped with a PHASER olfactory port (GL Sciences, Inc., Tokyo, Japan) and a HP5 MS capillary column $(30 \mathrm{~m} \times 0.25 \mathrm{~mm} \times 0.25 \mu \mathrm{m}$, Agilent technologies). Analytical conditions were the same as those for GC-MS analysis. Olfactometry analysis for aroma compounds of baby ginger paocai was performed by three skilled panellists and repeated twice by each assessor. Referring to previous research conclusions $[15,16]$, aroma extract dilutions analysis (AEDA) by adjusting split ratio was a better method for GC-O analysis. In this study, split ratios $10: 1$, 


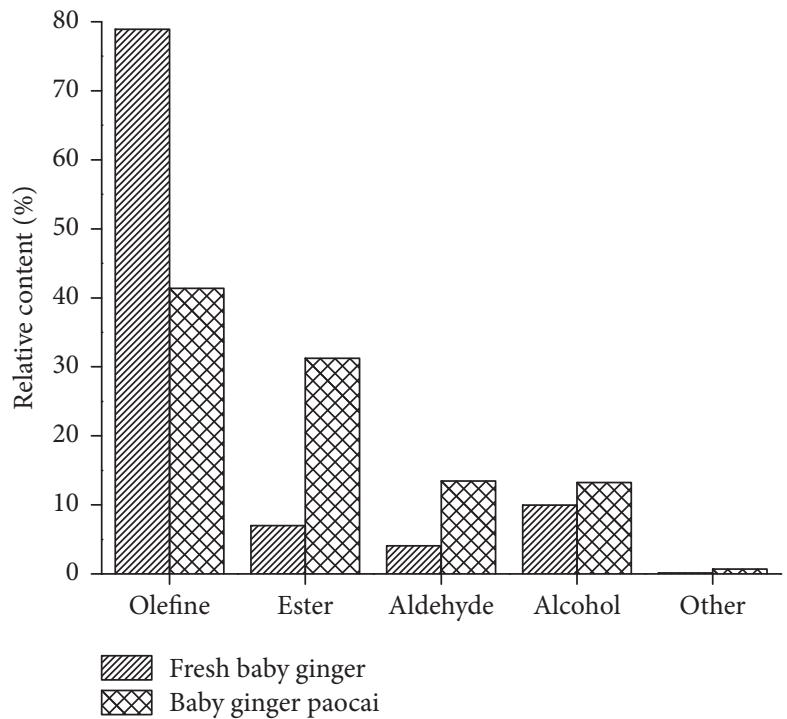

(a) Percentage of olefine, ester, aldehyde, alcohol, and other compounds

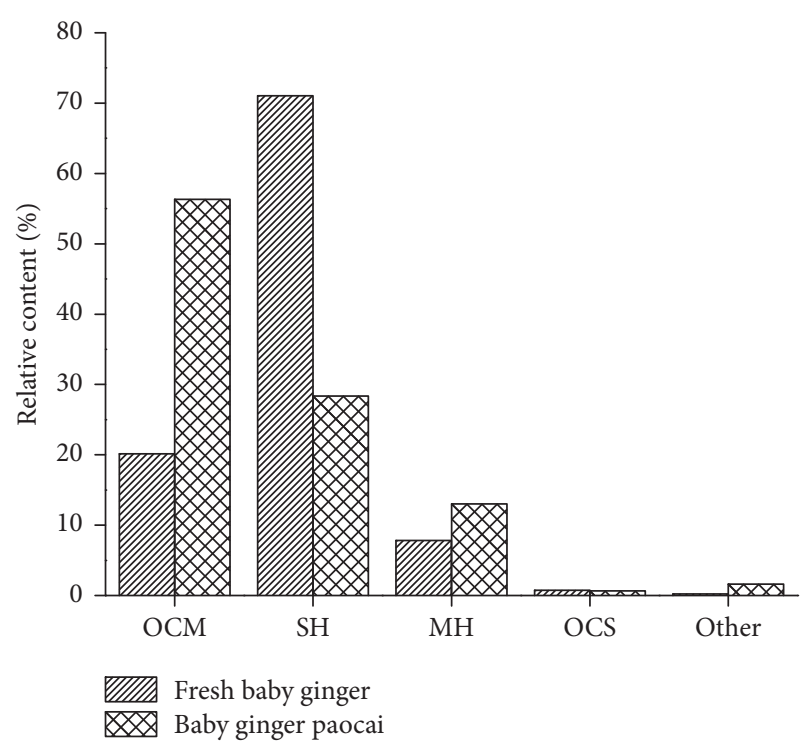

(b) Percentage of OCM, SH, MH, OCS, and other compounds

Figure 1: Percentage of the different chemical groups of components present in the two baby ginger samples.

$25: 1,50: 1,100: 1$, and $200: 1$ were used while splitless mode was not considered. There was a flavor dilution (FD) factor evaluating the activity of aroma compounds. The FD factor of an aroma-active compound represented the highest split ratio at which the compound could be detected at the sniffing port. Then, the FD factor was defined as the dilution step at which a compound was detected at least half of the six times.

\section{Results and Discussion}

After being concentrated by the SPME fiber on the optimal extraction conditions, the volatile compounds of baby ginger samples were separated and detected under the beforementioned GC-MS conditions. The total ion current (TIC) chromatogram for the aromatic compounds of each baby ginger sample was obtained by GC-MS.

According to the results of qualitative analysis, there were 86 volatile compounds identified in the two baby ginger samples. The results of GC-MS analysis were listed in Table 1. In the pickled baby ginger, there were 58 volatile compounds, whose mass concentrations add up to $931.8 \mathrm{mg} / \mathrm{kg}$, belonging to different chemical classes: olefines (32), esters (11), alcohols (8), aldehydes (3), ketones (3), and furan (1). However, the volatile compounds of the fresh baby ginger belonged to different chemical classes: olefines (51), esters (9), alcohols (14), aldehydes (2), ketones (1), and alkane (1); the sum of their mass concentrations was $2012.8 \mathrm{mg} / \mathrm{kg}$. Percentage of the different chemical groups of components present in the two ginger samples was shown in Figure 1. The aroma compounds present were in a dynamic state of change over the fermentation period as some components increased and other components decreased. This result implied that the overall aroma characteristics also changed during the fermentation.

As seen from Figure 1(a), the principal volatile constituents of the fresh baby ginger or baby ginger paocai consisted of olefines, esters, alcohols, and aldehydes. Among them, olefine was the material type with the highest content. Compared with the fresh baby ginger, baby ginger paocai had less volatile olefines and more volatile esters, in terms of either relative content or absolute content (mass concentration); furthermore, in terms of absolute content, baby ginger paocai had less volatile alcohols and had more volatile aldehydes or ketones; in terms of relative content, baby ginger paocai had more volatile alcohols or aldehydes or ketones. So we could infer that olefine was one of the main volatile components in fresh baby ginger. This result is similar to the results of previous studies on ginger samples $[3,12]$. Furthermore, ester might be one of the main volatile components in baby ginger paocai, while some scholars such as Xu et al. [17], Liu et al. [18], and Wu et al. [19] also considered ester as one of the main characteristics of pickles.

The volatile compounds listed in Table 1 largely belonged to terpenoids or their derivatives, for example, monoterpene hydrocarbons $(\mathrm{MH})$, sesquiterpene hydrocarbons $(\mathrm{SH})$, oxygen-containing monoterpenes (OCM), and oxygencontaining sesquiterpenes (OCS); this result was consistent with the result of Angel et al. [20] who studied essential oil composition of several starchy Curcuma species. The composition of terpenoids in the two baby ginger samples was shown in Figure 1(b). Monoterpene hydrocarbons $(\mathrm{MH})$, sesquiterpene hydrocarbons $(\mathrm{SH})$, and oxygen-containing monoterpenes (OCM) were the principal volatile constituents of the fresh baby ginger or baby ginger paocai. In terms of absolute content, baby ginger paocai had less monoterpene hydrocarbons $(\mathrm{MH})$ or sesquiterpene hydrocarbons $(\mathrm{SH})$ than the 


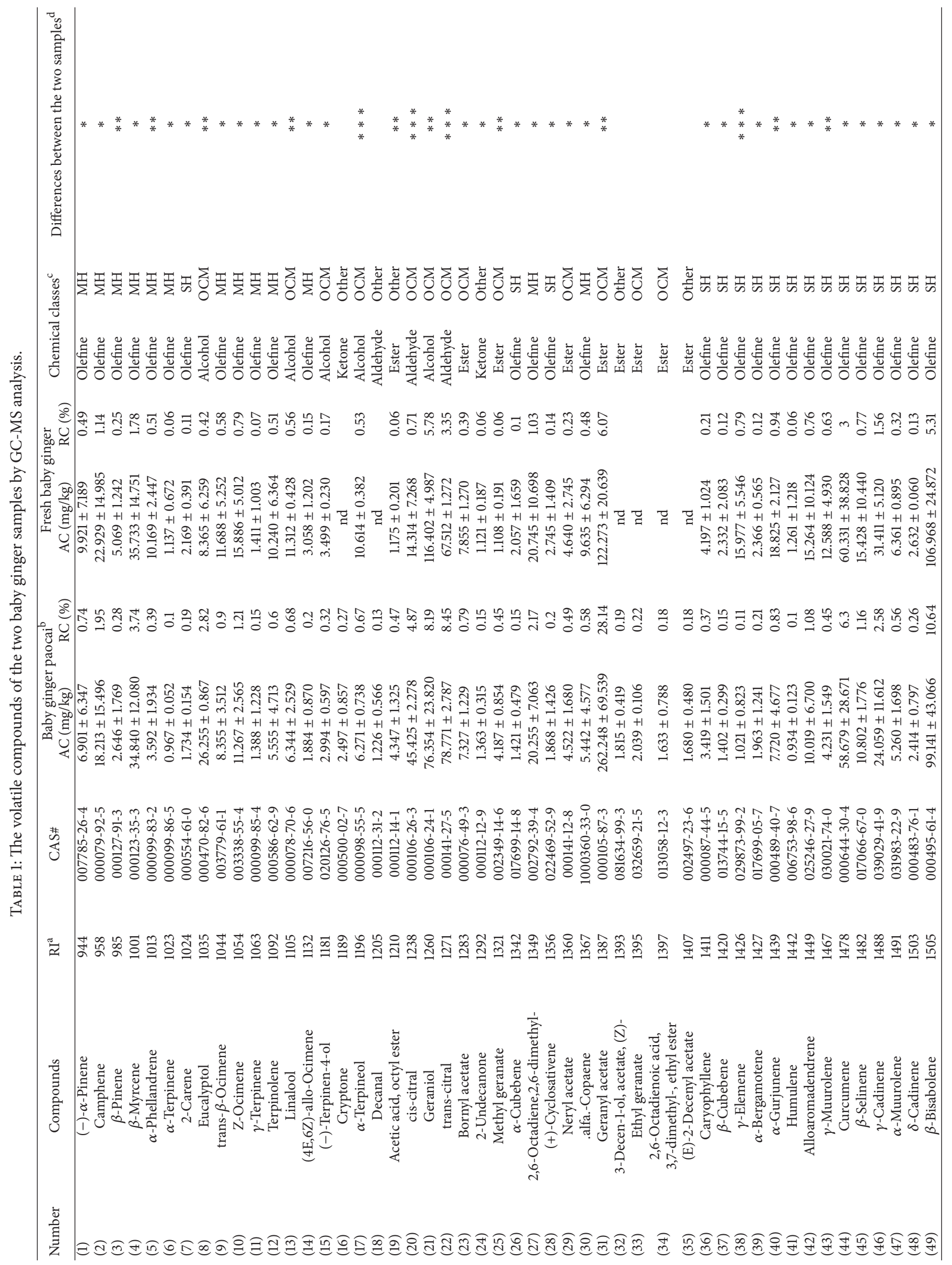




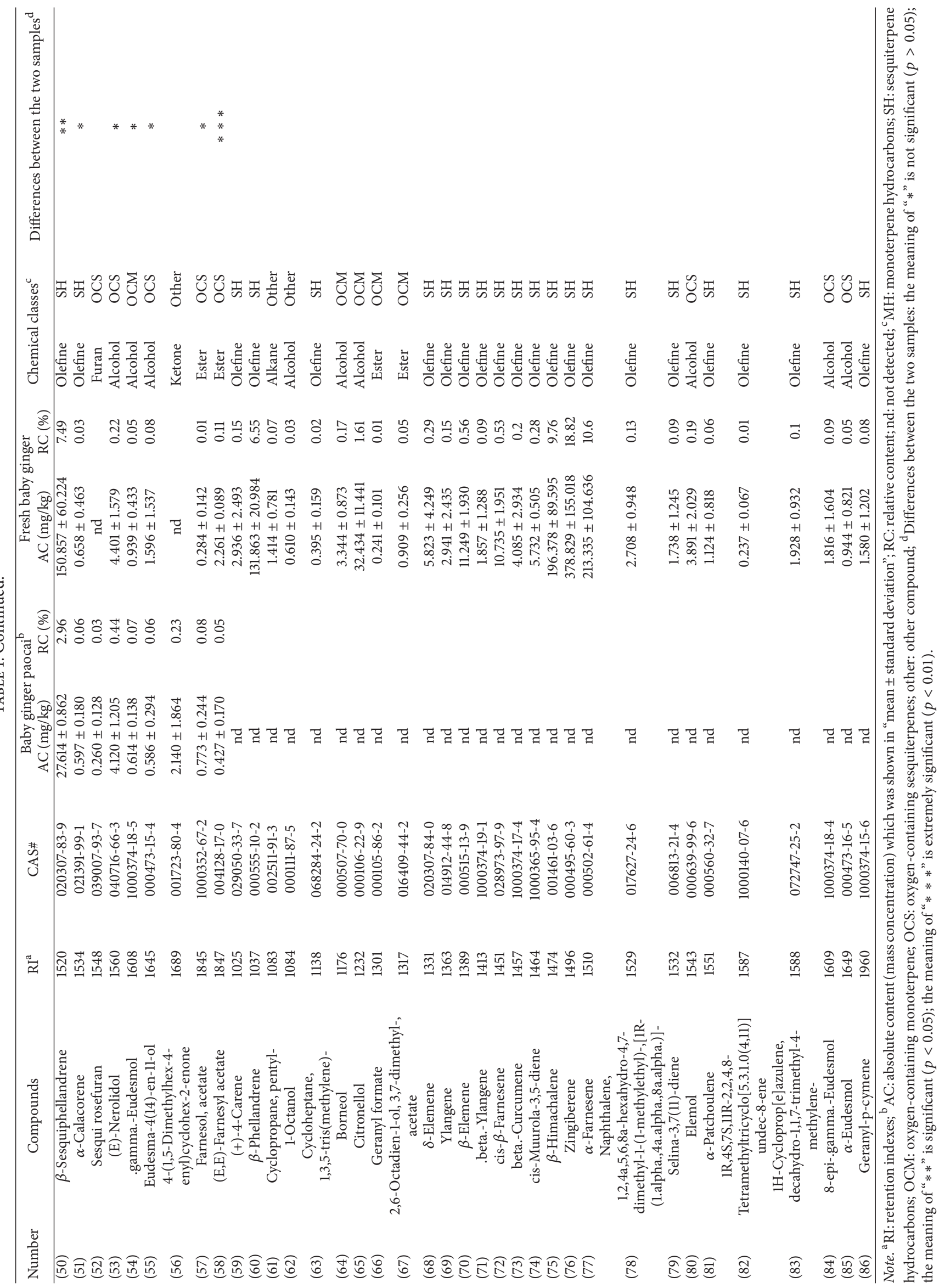


fresh baby ginger. However, in terms of either absolute content or relative content, baby ginger paocai had more oxygencontaining monoterpenes (OCM) than the fresh baby ginger. In baby ginger paocai, oxygen-containing monoterpenes (OCM), which was a type of terpenoid with relative content of $56.34 \%$ and far more than the other terpenoids, consisted of 8 alcohols (12.75\%), 2 aldehydes (13.32\%), and 8 esters $(30.27 \%)$. In the fresh baby ginger, the content of oxygencontaining monoterpenes (OCM) was only $20.16 \%$ while relative content of sesquiterpene hydrocarbons $(\mathrm{SH})$ was $71.06 \%$ and far more than that of the other terpenoids. So we could conjecture that oxygen-containing monoterpenes (OCM) belonged to the characteristic flavor components of baby ginger paocai, and this process phenomenon could be caused by the accumulation of esters in the fermentation process of baby ginger paocai. The result again confirmed that esters were the characteristic components of pickles.

In the fresh baby ginger samples, geraniol $(21,5.78 \%)$, geranyl acetate $(31,6.07 \%), \beta$-bisabolene $(49,5.31 \%), \beta$ sesquiphellandrene $(50,7.49 \%), \beta$-phellandrene $(60,6.55 \%)$, $\beta$-himachalene $(75,9.76 \%)$, zingiberene $(76,18.82 \%)$, or $\alpha$ farnesene $(77,10.60 \%)$ was the compound with an absolute content exceeding $100 \mathrm{mg} / \mathrm{kg}$, and they could belong to the main flavor components of the fresh baby ginger. The relatively high contents of $\beta$-bisabolene (49), $\beta$-sesquiphellandrene (50), $\beta$-phellandrene (60), and zingiberene (76) account for the odor of the fresh baby ginger, which was consistent with the result of Huang et al. [12] and An et al. [3]. Geranial, zingiberene (76), or $\alpha$-farnesene (77) was considered by Bartley and Jacobs [11] to be one of the main flavor fractions of Australian-grow ginger. $\beta$ himachalene (75) had never been listed as a characteristic component in the past literature on the analysis of volatile compounds of ginger. The differences in the main volatile composition may be attributed to not only methods of extraction for volatile compounds [13], but also the quality of ginger which is closely related to the different origins of ginger, cultivation techniques, harvest time, and other factors [21].

In baby ginger paocai, geranyl acetate $(31,28.14 \%)$ was the only compound with an absolute content exceeding $100 \mathrm{mg} / \mathrm{kg}$, while $\beta$-bisabolene $(49,10.64 \%)$, trans-citral (22, $8.45 \%)$, geraniol $(21,8.19 \%)$, curcumene $(44,6.3 \%)$, and cis-citral $(20,4.87 \%)$ were also among the main volatile components. The relatively high content of esters accounts for the odor of the baby ginger paocai, which was consistent with the result of $\mathrm{Xu}$ et al. [17] and Liu et al. [18]. Some volatile compounds, which were the major components of the fresh baby ginger, were not detected in baby ginger paocai, for example, $\beta$-phellandrene (60), $\beta$-himachalene (75), zingiberene (76), and $\alpha$-farnesene (77). There were still some volatile compounds detected in the fresh baby ginger, but not detected in baby ginger paocai, such as octanol (62), borneol (64), citronellol (65), and elemol (80). Furthermore, there were 8 volatile compounds, which were not detected in the fresh baby ginger but detected in baby ginger paocai, consisting of cryptone $(16,0.27 \%)$, decanal $(18,0.13 \%), 3$-decen1 -ol, acetate, $(Z)-(32,0.19 \%)$, ethyl geranate $(33,0.22 \%)$, 2,6-octadienoic acid, 3,7-dimethyl-, ethyl ester (34, 0.18\%),
(E)-2-decenyl acetate $(35,0.18 \%)$, sesqui rosefuran (52, $0.03 \%)$, and 4-(1,5-dimethylhex-4-enyl) cyclohex-2-enone $(56,0.23 \%)$. The 8 volatile compounds might be the intermediary or the final metabolite of microbial metabolism. Sulfurcontaining compound was not detected in this study while it was one of the characteristic aroma components of pickles $[17,19]$. This difference should be directly related to the raw materials of pickles.

The preceding difference in flavor composition of the two baby ginger samples is intrinsically related to microbial fermentation and the dissolution of some flavor compounds. As mentioned earlier by scholars, kimchi fermentation process is achieved by bacteria, yeasts, fungi, and other microorganisms; lactic acid bacteria are the most important microorganisms which affect the sensory quality of pickled vegetables. The formation of flavor is a complicated process that occurs during homolactic and heterolactic fermentation by lactic acid bacteria [22]. Some of the metabolites in the microbial fermentation process react with certain ingredients in the vegetables to produce new substances, so that the flavor composition of vegetables could be improved [19].

The contribution of each volatile substance to the flavor of baby ginger paocai is not only related to its relative content, but also related to its absolute content and sensory threshold. So the aroma composition of baby ginger paocai was analyzed by GC-O method in the study. In the sensory evaluation, baby ginger paocai exhibited overall "spicy," "camphor-like," "herbal," "fruity," "flowery," "ginger-like," and "balsamic" aroma qualities. The highest sensory scores were for gingerlike, camphor-like, flowery, and fruity aroma, while the lowest score was for woody note. With the increase of the split ratio from $10: 1$ to $200: 1$, the paocai volatile extracts of HS-SPME fiber were diluted. Fifty-eight aroma-active compounds were identified (Table 2).

Woody and camphor-like were perceived at lower retention indices, followed by balsamic, flowery, spicy, and fruity. At the end of the analysis the camphor-like quality appeared again, followed by the fruity. Compounds with a balsamic note (4), camphor-like note (8), flowery note $(9,10,13,18,20$, and 21$)$, fruity note $(31,49)$, and ginger-like note (44) were the most important aroma-active components in baby ginger paocai. Most of these aroma compounds correlated well with the sensory attributes detected in sensory evaluation. These eleven odorants were all detected in fresh baby ginger except for decanal (18). Decanal (18) might be the product of lactobacillus fermentation.

A strong fruity note was found to be the characteristic flavor of baby ginger paocai, compared with fresh baby ginger. The pleasant fruity note of baby ginger paocai could be attributed to the combined effects of cis-citral (20), geranyl acetate (31), and $\beta$-bisabolene (49). The three aroma-active components had high FD values $(200: 1)$; their accumulation may be due to the relatively long fermentation time and lactic acid fermentation stage involved in the production of baby ginger paocai. Geranyl acetate (31) was found at a relatively high concentration ( $>200 \mathrm{mg} / \mathrm{kg}$ ) in baby ginger paocai and had a low aroma threshold in water $(0.15 \mathrm{mg} / \mathrm{kg})$ [23]. This result again confirmed that geranyl acetate (31) was a characteristic aroma component of baby ginger paocai. Volatile 


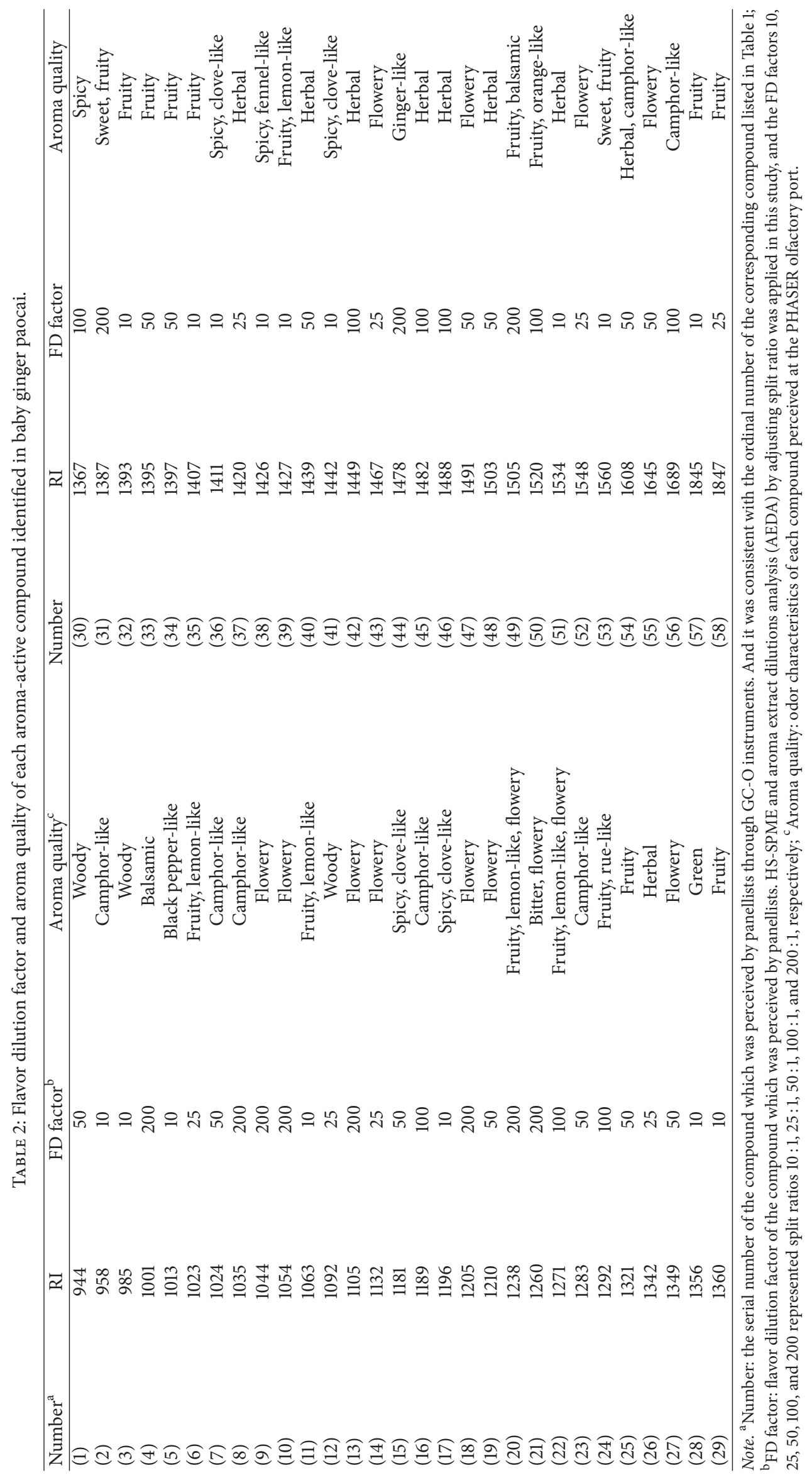


esters except for acetic acid, octyl ester (19), and bornyl acetate (23) were fruity for the aroma quality of baby ginger paocai, which was in accordance with the result of Wu et al. [19]. All volatile esters except for farnesol, acetate (57), and (E,E)-farnesyl acetate (58) belonged to the body note of baby ginger paocai.

The camphor-like note was a part of the typical aroma of baby ginger paocai while camphor was considered by Angel et al. [20] to be a characteristic component in ginger. However, camphor was not detected in baby ginger paocai or the fresh baby ginger. Eucalyptol (8) was one of the most intense camphor-like odorants (split ratio 200:1) in this study, and it belonged to the top note of baby ginger paocai. Eucalyptol (8) had a low aroma threshold in water $(0.0046 \mathrm{mg} / \mathrm{kg})$ [24], and its absolute content was $26.255 \mathrm{mg} / \mathrm{kg}$. As important parts of the camphor-like compounds, cryptone (16) and 4-(1,5dimethylhex-4-enyl)cyclohex-2-enone (56) belonged to the body note and the base note, respectively.

Regarding flowery notes, compounds trans- $\beta$-ocimene (9), Z-ocimene (10), linalool (13), and decanal (18) were detected with high FD factors $(200: 1)$. The odor thresholds of the four substances were $0.034 \mathrm{mg} / \mathrm{kg}$ [25], $0.034 \mathrm{mg} / \mathrm{kg}$ [25], $0.006 \mathrm{mg} / \mathrm{kg}$ [23], and $0.003 \mathrm{mg} / \mathrm{kg}$ [26] for compounds 9,10 , 13 , and 18, respectively. Decanal (18) was one of metabolic products in the fermentation process of baby ginger. Sesqui rosefuran (52) could be transformed from cis- $\beta$-farnesene (72) or $\alpha$-farnesene (77). Cis-citral (20) and trans-citral (22) also were flowery. All the flowery compounds of baby ginger paocai belonged to its body note.

\section{Conclusions}

The results obtained by analyzing aroma compounds of baby ginger paocai and fresh baby ginger demonstrated that the aroma formation of baby ginger was significantly changed by lactic acid fermentation. The main ingredients of fresh baby ginger or baby ginger paocai belonged to alcohols, aldehydes, olefines, and esters. These volatile aroma compounds were mostly terpenoids or their derivatives. $\beta$-myrcene (4), eucalyptol (8), trans- $\beta$-ocimene (9), Z-ocimene (10), linalool (13), decanal (18), cis-citral (20), geraniol (21), geranyl acetate (31), curcumene (44), and $\beta$-bisabolene (49) were all the crucial aromatic components with more significant sensory contribution to the overall flavor of the product of baby ginger paocai which had experienced a moderate fermentation process.

\section{Additional Points}

Practical Application. Baby ginger, as a vegetable, is not only directly used as a raw material for cooking, but also salted into a baby ginger paocai (which is a Chinese pickle). This research analyzed the aroma composition of baby ginger paocai and found the key aroma-active compounds. These results will be helpful to the process optimization and quality control of baby ginger paocai.

\section{Conflicts of Interest}

The authors declare that there are no conflicts of interest regarding the publication of this paper.

\section{Authors' Contributions}

The design of this research was accomplished by Songming Luo and guided by Biao Pu. Songming Luo interpreted the results and drafted the manuscript. Qiang Li, Anjun Chen, and Xingyan Liu collected test data.

\section{Acknowledgments}

This study was supported financially by National Natural Science Foundation of China (Grant no. 31171726) and Science and Technology Project of Sichuan Province (Grant no. 2012NZ0002). Thanks are due to Songming Luo's wife for her great support for this work. And thanks are also due to individuals who have participated in this work.

\section{References}

[1] T. Carman, Growing baby ginger: farmers find it's worth the fuss. The Washington Post. Available from: http://articles.washingtonpost.com/2011-10-18/lifestyle/35280435_1_ginger-maturerhizomes-crop.

[2] J. Liu, G. Sui, Y. He et al., "Prolonging storage time of baby ginger by using a sand-based storage medium and essential oil treatment," Journal of Food Science, vol. 79, no. 4, pp. M593M599, 2014.

[3] K. An, D. Zhao, Z. Wang, J. Wu, Y. Xu, and G. Xiao, "Comparison of different drying methods on Chinese ginger (Zingiber officinale Roscoe): Changes in volatiles, chemical profile, antioxidant properties, and microstructure," Food Chemistry, vol. 197, pp. 1292-1300, 2016.

[4] T. Xiong, Q. Guan, S. Song, M. Hao, and M. Xie, "Dynamic changes of lactic acid bacteria flora during Chinese sauerkraut fermentation," Food Control, vol. 26, no. 1, pp. 178-181, 2012.

[5] W. Liu, L. Zhang, J. Shi et al., "Assessment of the safety and applications of bacteriocinogenic Enterococcus faecium Y31 as an adjunct culture in North-eastern Chinese traditional fermentation paocai," Food Control, vol. 50, pp. 637-644, 2015.

[6] Q. Zhang, G. Chen, W. Shen, Y. Wang, W. Zhang, and Y. Chi, "Microbial safety and sensory quality of instant low-salt Chinese paocai," Food Control, vol. 59, pp. 575-580, 2016.

[7] J. Bautista-Gallego, K. Rantsiou, A. Garrido-Fernández, L. Cocolin, and F. N. Arroyo-López, "Salt reduction in vegetable fermentation: Reality or desire?" Journal of Food Science, vol. 78, no. 8, pp. R1095-R1100, 2013.

[8] H. Cheng, J. Chen, S. Chen, D. Wu, D. Liu, and X. Ye, "Characterization of aroma-active volatiles in three Chinese bayberry (Myrica rubra) cultivars using GC-MS-olfactometry and an electronic nose combined with principal component analysis," Food Research International, vol. 72, pp. 8-15, 2015.

[9] Y. Yu, T. Huang, B. Yang, X. Liu, and G. Duan, "Development of gas chromatography-mass spectrometry with microwave distillation and simultaneous solid-phase microextraction for rapid determination of volatile constituents in ginger," Journal of Pharmaceutical and Biomedical Analysis, vol. 43, no. 1, pp. 2431, 2007. 
[10] P. Chavalittumrong and W. Jirawattanapong, "Variation of active constituents of Curcuma domestica rhizome at different age," Thai Journal of Pharmaceutical Sciences, vol. 16, pp. 165174, 1992.

[11] J. P. Bartley and A. L. Jacobs, "Effects of drying on flavour compounds in Australian-grown ginger (Zingiber officinale)," Journal of the Science of Food and Agriculture, vol. 80, no. 2, pp. 209-215, 2000.

[12] B. Huang, G. Wang, Z. Chu, and L. Qin, "Effect of Oven Drying, Microwave Drying, and Silica Gel Drying Methods on the Volatile Components of Ginger (Zingiber officinale Roscoe) by HS-SPME-GC-MS," Drying Technology, vol. 30, no. 3, pp. 248255, 2012.

[13] S. H. Ding, K. J. An, C. P. Zhao, Y. Li, Y. H. Guo, and Z. F. Wang, "Effect of drying methods on volatiles of Chinese ginger (Zingiber officinale Roscoe)," Food and Bioproducts Processing, vol. 90, no. 3, pp. 515-524, 2012.

[14] W. Kang, Y. Li, Y. Xu, W. Jiang, and Y. Tao, "Characterization of Aroma Compounds in Chinese Bayberry (Myrica rubra Sieb. et Zucc.) by Gas Chromatography Mass Spectrometry (GC-MS) and Olfactometry (GC-O)," Journal of Food Science, vol. 77, no. 10, pp. C1030-C1035, 2012.

[15] J. Zhao, X. Dai, X. Liu, H. Zhang, J. Tang, and W. Chen, "Comparison of aroma compounds in naturally fermented and inoculated Chinese soybean pastes by GC-MS and GCOlfactometry analysis," Food Control, vol. 22, no. 6, pp. 10081013, 2011

[16] Y. Feng, Y. Cai, D. Sun-Waterhouse et al., "Approaches of aroma extraction dilution analysis (AEDA) for headspace solid phase microextraction and gas chromatography-olfactometry (HSSPME-GC-O): Altering sample amount, diluting the sample or adjusting split ratio?” Food Chemistry, vol. 187, pp. 44-52, 2015.

[17] D. Xu, B. Pu, A. Chen, and Z. Zhuo, "Analysis of volatile compounds in traditional Sichuan pickles," in Food and Fermentation Industries, vol. 40, pp. 227-232, 11 edition, 2014.

[18] C. Liu, M. Dai, J. Xia, T. Zhou, L. Shen, and B. Pu, "Study on the flavor of different lactic acid bacteria inoculated fermentation pickle," Science and Technology of Food Industry, vol. 36, no. 07, pp. 154-158, 2015 (Chinese).

[19] R. Wu, M. Yu, X. Liu et al., "Changes in flavour and microbial diversity during natural fermentation of suan-cai, a traditional food made in Northeast China," International Journal of Food Microbiology, vol. 211, pp. 23-31, 2015.

[20] G. R. Angel, N. Menon, B. Vimala, and B. Nambisan, "Essential oil composition of eight starchy Curcuma species," Industrial Crops and Products, vol. 60, pp. 233-238, 2014.

[21] B. Manochai, Y. Paisooksantivatana, H. Choi, and J. H. Hong, "Variation in DPPH scavenging activity and major volatile oil components of cassumunar ginger, Zingiber montanum (Koenig), in response to water deficit and light intensity," Scientia Horticulturae, vol. 126, no. 4, pp. 462-466, 2010.

[22] J. Y. Jung, S. H. Lee, and C. O. Jeon, "Kimchi microflora: History, current status, and perspectives for industrial kimchi production," Applied Microbiology and Biotechnology, vol. 98, no. 6, pp. 2385-2393, 2014.

[23] J. A. Pino and J. Mesa, "Contribution of volatile compounds to mango (Mangifera indica L.) aroma," Flavour and Fragrance Journal, vol. 21, no. 2, pp. 207-213, 2006.

[24] M. Czerny, M. Christlbauer, M. Christlbauer et al., "Reinvestigation on odour thresholds of key food aroma compounds and development of an aroma language based on odour qualities of defined aqueous odorant solutions," European Food Research and Technology, vol. 228, no. 2, pp. 265-273, 2008.

[25] H. Tamura, S. Boonbumrung, T. Yoshizawa, and W. Varanyanond, "The Volatile Constituents in the Peel and Pulp of a Green Thai Mango, Khieo Sawoei Cultivar (Mangifera indica L.)," Food Science and Technology Research, vol. 7, no. 1, pp. 72-77, 2001.

[26] M. Averbeck and P. Schieberle, "Influence of different storage conditions on changes in the key aroma compounds of orange juice reconstituted from concentrate," European Food Research and Technology, vol. 232, no. 1, pp. 129-142, 2011. 

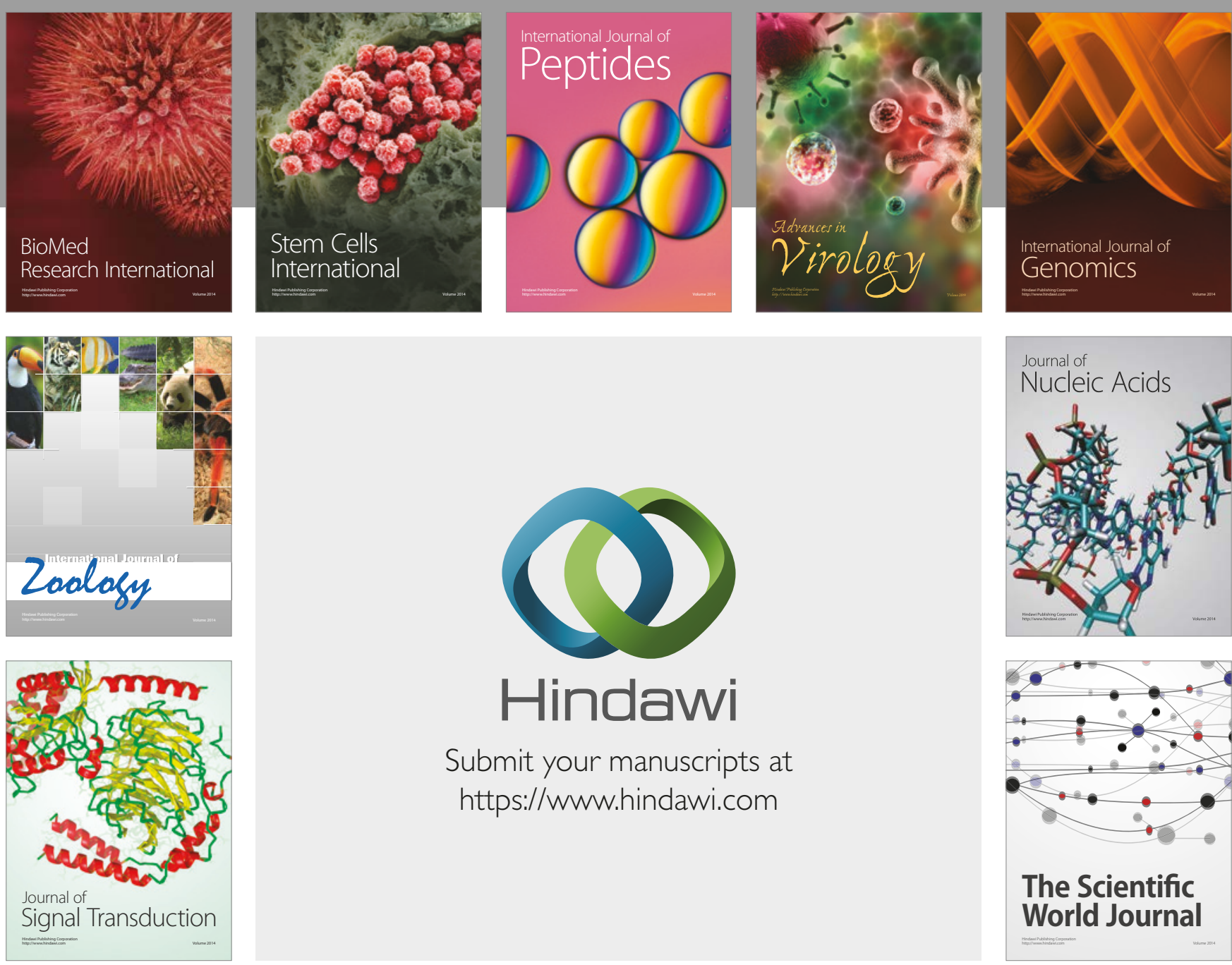

Submit your manuscripts at

https://www.hindawi.com
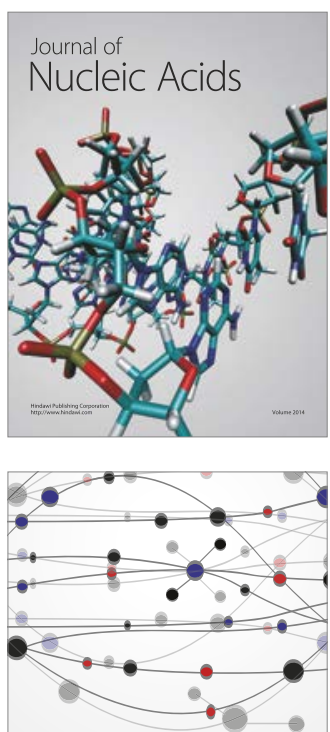

The Scientific World Journal

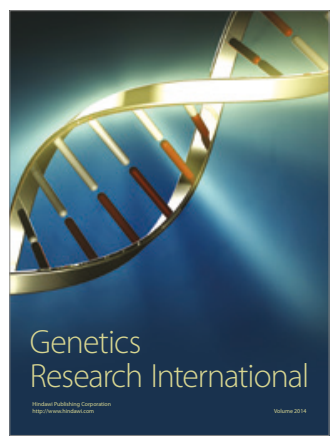

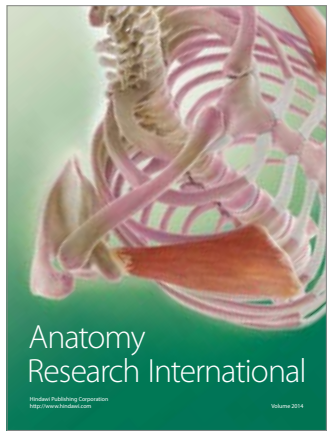

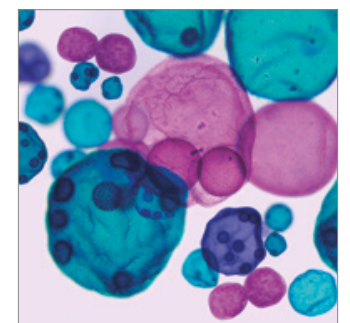

International Journal of Microbiology
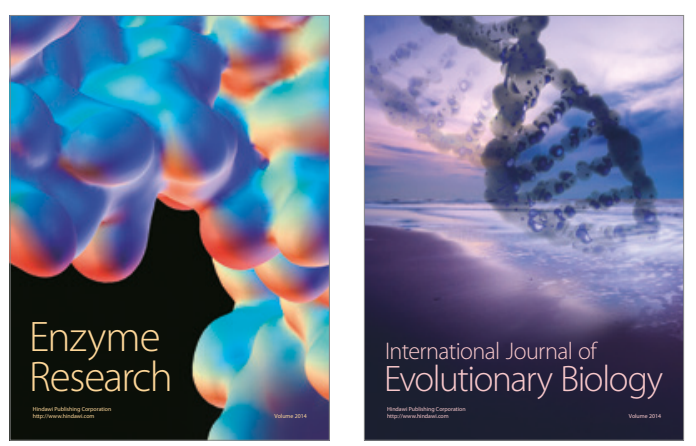
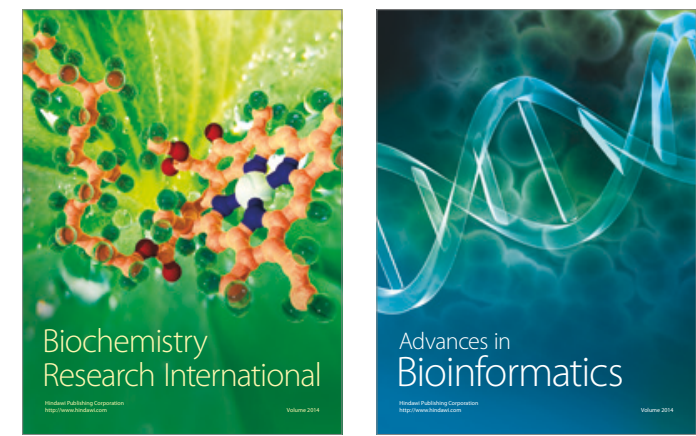

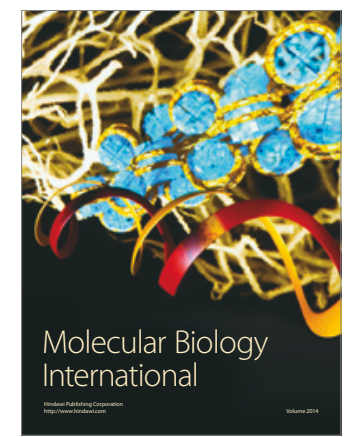

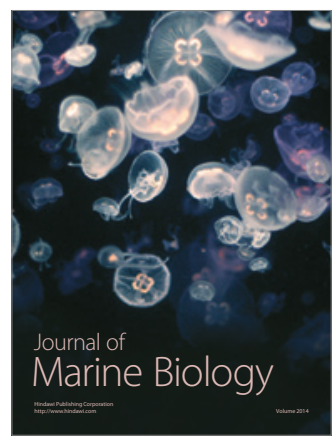

